\title{
Grupo de acompanhantes de crianças internadas em Unidade de Terapia Intensiva
}

\author{
Fernanda Rodrigues da Silva ${ }^{a}$, Maria Luisa Gazabim Simóes Ballarin ${ }^{\mathrm{b}}$, José Carlos Oliveira ${ }^{\mathrm{c}}$ \\ ${ }^{\text {a}}$ Hospital e Maternidade Celso Pierro, Pontifícia Universidade Católica de Campinas - PUC-Campinas, \\ Campinas, SP, Brasil.

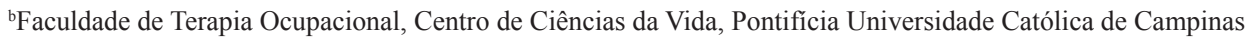 \\ - PUC-Campinas, Campinas, SP, Brasil. \\ 'Faculdade de Enfermagem, Centro de Ciências da Vida, Pontifícia Universidade Católica de Campinas - PUC- \\ Campinas, Campinas, SP, Brasil.
}

\begin{abstract}
Resumo: Este trabalho é resultado da experiência de intervenção terapêutica ocupacional junto a um grupo de acompanhantes de crianças internadas em uma UTI Pediátrica, dentro de um Programa de Residência Multiprofissional, em um Hospital Universitário de um município do interior do Estado de São Paulo. Caracteriza-se como um trabalho de natureza descritiva e qualitativa, realizado a partir das observações clínicas e dos registros dos atendimentos efetivados, semanalmente, pelo terapeuta ocupacional, no período de outubro de 2013 a junho de 2014. Os objetivos estabelecidos no plano de intervenções ao grupo foram: possibilitar ao grupo de acompanhantes a saída do ambiente da UTI Pediátrica; construir um espaço mais humanizado que favorecesse o diálogo e a troca de experiências entre os acompanhantes; orientar quanto às condições de saúde da criança e prepará-los para etapas subsequentes do tratamento; auxiliar na reorganização da rotina da casa; fomentar a ampliação da rede de apoio social; criar espaços dirigidos ao autocuidado. Atividades expressivas, produtivas e de lazer/sociais, assim como dinâmicas grupais, funcionaram como estratégias para que se alcançassem os objetivos estabelecidos ao longo do processo de intervenção. A experiência mostrou-se positiva e benéfica, na medida em que o grupo de acompanhantes pôde trocar experiências e sentimentos, oferecendo apoio uns aos outros e desenvolvendo novas habilidades no que se refere ao enfrentamento da internação. Puderam ainda estreitar o vínculo com a criança internada e vivenciar o ambiente hospitalar de forma mais humanizada e acolhedora. As intervenções terapêuticas ocupacionais realizadas indicam que as estratégias grupais propostas e desenvolvidas foram efetivas.
\end{abstract}

Palavras-chave: Terapia Ocupacional, Processos Grupais, Cuidados Intensivos, Pediatria.

\section{Group of Intensive Care Unit hospitalized children chaperone}

\begin{abstract}
This work is the result of occupational therapy intervention experience with a group of chaperons of pediatric ICU hospitalized children, in a multidisciplinary residency program at a university hospital in a city of the state of São Paulo. It is characterized as a work of descriptive and qualitative nature, performed based on clinical observations and records of weekly visits accomplished, by the occupational therapist, from October 2013 to June 2014. The goals set out in the groups's intervention plan to the group were to enable the output of the Pediatric ICU environment for the chaperone group; building a more humane space that favored dialogue and the exchange of experiencesamong them; advising on child health conditions and prepare them for subsequent treatment steps; assisting in the reorganization of the home routine; promoting the expansion of the network of social support; creating spaces directed to self-care. Expressive, productive and recreational/social activities as well as group
\end{abstract}

Autor para correspondência: Fernanda Rodrigues da Silva, Hospital e Maternidade Celso Pierro, Avenida John Boyd Dunlop, s/n, Jardim Ipaussurama, Campus II, CEP 13060-904, Campinas, SP, Brasil, e-mail: fernandarodrigues.to@gmail.com

Recebido em Dez. 16, 2014; $1^{\text {a }}$ Revisão em Maio 4, 2015; Aceito em Ago. 31, 2015. 
dynamics worked as strategies to achieve the goals set during the intervention process. The experience was positive and beneficial, according as the group of companions could exchange experiences and feelings, offering support one to another and developing new skills in relation to facing hospitalization. They might even narrow the bond with the hospitalized child and experience the hospital environment more humane and warm welcome. Occupational therapy interventions indicate that the group strategies proposed and developed were effective.

Keywords: Occupational Therapy, Group Processes, Intensive Care, Pediatric.

\section{Introdução}

Embora o hospital funcione como um estabelecimento destinado ao diagnóstico e ao tratamento de doentes, e, portanto, cumpre a função de cura do doente, este também se caracteriza como um local de separaçáo, na medida em que a pessoa a ser hospitalizada é lançada em um ambiente que obedece a regras próprias, diferentes das existentes em seu meio particular (TORRES et al., 1987). Assim, o ambiente hospitalar por si só constitui-se um local gerador de desgaste de vários tipos, alguns relacionados diretamente ao doente, aos seus familiares e à própria equipe de profissionais que nele atuam.

Durante a internação de um paciente, há uma ruptura de seu cotidiano, pois ele está submetido à rotina hospitalar. Quando a internação é prolongada, provoca um afastamento das atividades cotidianas e o paciente passa a viver em um ambiente muito diferente do ambiente social, sendo impossibilitado, muitas vezes, de executar as atividades mais simples do seu dia a dia (RIBEIRO; BERNAL; ZAPONI, 2008).

A situação fica ainda mais complexa quando há a necessidade de internaçáo em uma Unidade de Terapia Intensiva - UTI. Segundo Almeida et al. (2009), os sentimentos de familiares durante a internação de parentes na UTI foram descritos e subcategorizados em: ansiedade; preocupação; angústia e tristeza; impotência; medo e pânico; confiança e segurança; insegurança; fé e esperança, entre outros. De certo modo, tais sentimentos podem ser explicados, na medida em que as UTIs destinam-se ao atendimento de pacientes que se encontram em estados potencialmente graves, necessitando de assistência contínua e tratamento intensivo, realizado por equipe multidisciplinar, além de ser um sistema de monitorização e suporte 24 horas. As questôes ficam ainda mais difíceis quando a pessoa a ser inserida em UTI é um bebê ou uma criança.

De modo geral, os hospitais possuem Unidades de Terapia Intensiva diferenciadas para o atendimento de pacientes adultos e crianças, havendo ainda uma distinção entre UTI Neonatal e UTI Pediátrica. A UTI Neonatal destina-se à assistência a pacientes admitidos com idade entre zero e 28 dias, enquanto a UTI Pediátrica propóe assistência a pacientes com idade de 29 dias a 14 ou 18 anos, sendo este limite definido de acordo com as rotinas da instituição (BRASIL, 2010).

Alguns estudos vêm abordando UTI como um lugar de tensôes constantes, em que profissionais experimentam uma vivência de angústia e estresse (GOMES; LUNARDI FILHO; ERDMANN, 2006; MIRANDA; STANCATO, 2008). É neste contexto de trabalho que se pode inserir o terapeuta ocupacional. Esse profissional deve estar integrado às demais atividades assistenciais prestadas ao paciente, sendo discutidas conjuntamente pela equipe multiprofissional, conforme descrito no Art. 23, da seção V, da Resolução 7 de 24 de fevereiro de 2010 (BRASIL, 2010).

Ressalta-se que, embora a inclusão de terapeutas ocupacionais em UTI seja prevista por lei, sua inserção na equipe é relativamente recente. Do mesmo modo, publicações especializadas sobre intervenções deste profissional em contextos hospitalares, bem como a assistência aos acompanhantes de crianças hospitalizadas e em UTI, são escassas, o que justifica o desenvolvimento deste trabalho. Portanto, é no contexto de uma UTI pediátrica que se buscou desenvolver este estudo, que tem por objetivo descrever a experiência de um terapeuta ocupacional no atendimento a um grupo de acompanhantes de crianças internadas em UTI, dentro de um Programa de Residência Multiprofissional em um Hospital Universitário de um município do interior do Estado de São Paulo.

\section{Material e método}

O presente estudo caracteriza-se como um relato de experiência que descreve a atuação de um terapeuta ocupacional no desenvolvimento de um trabalho junto a um grupo de acompanhantes de crianças internadas em UTI Pediátrica. Trata-se de um estudo de natureza qualitativa e descritiva, elaborado a partir de observaçóes clínicas e dos registros dos atendimentos realizados pelo terapeuta ocupacional, no período de outubro de 2013 a junho de 2014 . 
Os registros eram elaborados imediatamente após $\mathrm{o}$ atendimento do grupo.

Segundo Triviños (1987), nas investigaçōes qualitativas, o ambiente, o contexto no qual os indivíduos realizam suas açóes e desenvolvem seu modo de vida, tem importância essencial na compreensão mais clara de suas atividades. $\mathrm{O}$ meio imprime ao sujeito que nele vive traços peculiares, que são desvendados à luz da compreensão dos significados que ele próprio estabelece. Ademais, a investigação qualitativa é predominantemente descritiva, buscando-se, assim, analisar os dados em toda sua riqueza, respeitando, no possível, a forma de registro.

Em específico, buscou-se compreender a vivência de um grupo de acompanhantes de crianças internadas em UTI pediátrica de um Hospital Universitário, situado em município do interior do Estado de São Paulo. Esta UTI possuía oito leitos e as crianças podiam ser acompanhadas por um dos pais durante 24 horas.

Os dados obtidos a partir dos registros foram analisados considerando-se os referenciais teóricos pertinentes à terapia ocupacional hospitalar que fundamentam este estudo. Neste contexto, entende-se que o relato de experiência é uma ferramenta de pesquisa que busca apresentar uma reflexão sobre uma ação ou um conjunto de açóes relacionadas à vivência no âmbito profissional, neste caso, do terapeuta ocupacional.

\section{Resultados e discussão}

A análise dos dados evidenciou aspectos relevantes pertinentes tanto ao contexto da UTI como às intervenções desenvolvidas junto aos acompanhantes das crianças internadas, os quais serão descritos a seguir.

\subsection{0 contexto da UTI pediátrica}

Como descrito anteriormente, a UTI Pediátrica do hospital em questão tem disponibilidade para oito leitos, sendo um deles destinado ao isolamento, servindo para internação de crianças com doenças que exijam precauçóes.

A faixa etária da população atendida compreende crianças com idades que variam entre 29 dias de vida e 12 anos e 11 meses, sendo os diagnósticos mais prevalentes: a Insuficiência Respiratória Aguda (IRA), o pós-operatório cardíaco, complicaçóes nefróticas, cirurgias infantis e traumatismo cranioencefálico (TCE).
Em consonância com o Estatuto da Criança e do Adolescente (ECA), na referida UTI Pediátrica, as crianças podem ser acompanhadas por um dos pais durante 24 horas, respeitando-se, assim, o pressuposto de que é direito da criança e do adolescente ter um acompanhante em tempo integral, conforme descrito no ECA (BRASIL, 1990). Porém, esses acompanhantes não ficam ao lado de sua criança durante o dia todo, apenas em momentos em que náo ocorrem procedimentos por parte da equipe de saúde com as crianças internadas.

Enfatiza-se que a estrutura física do referido setor não permite a permanência dos pais ao lado filho, já que não há espaço disponível para isso no saláo em que ficam os leitos. Existe uma pequena sala com oito poltronas, na qual os acompanhantes podem dormir e permanecer, que contém armários para que os pais possam guardar seus pertences, uma televisão e um ventilador afixados na parede, e um banheiro. Os acompanhantes têm direito a três refeiçôes diárias: café da manhã, almoço e jantar.

Apesar dos recursos existentes e disponíveis aos acompanhantes, a mudança de rotina, o afastamento das atividades cotidianas, incluindo o trabalho, o fato de estarem no mesmo ambiente por um longo período de tempo e a exposição a situaçôes adversas são fatores que tornam a estadia cansativa e estressante.

Todos os dias, o período das $15 \mathrm{~h} 30$ às $16 \mathrm{~h} 30$ é destinado aos pais, para que permaneçam junto aos seus filhos nos leitos. É também nesse mesmo horário que a equipe de profissionais apresenta o boletim médico comunicando-os sobre o estado de saúde de seus filhos. Nesse momento, os acompanhantes, na maioria mães e pais, podem conversar a respeito do estado de saúde de seus filhos. Esse modo de proceder da equipe médica da UTI corrobora com alguns estudos que ressaltam a importância dos esclarecimentos dos acompanhantes sobre a condiçâo de saúde das crianças. Isso se dá na medida em que tais esclarecimentos possibilitam que os mesmos criem estratégias de enfrentamento e participação no tratamento de seus filhos, ao longo da hospitalização (MILANESI et al., 2006; MENSORIO; KOHLSDORF, 2009; MORAES; COSTA, 2009).

Ainda em relação ao funcionamento da UTI, no período que vai das $19 \mathrm{~h} 30$ às $20 \mathrm{~h} 30$, o serviço libera a visita para três pessoas, além do acompanhante que está com a criança, e estas devem se revezar para entrar no espaço da UTI.

Ressalta-se que, nessa UTI, na maioria das vezes, os oito leitos pediátricos estão preenchidos. Nesse sentido, os acompanhantes dessas oito crianças acabam 
convivendo entre si e permanecendo praticamente durante o dia e a noite toda na sala reservada, condiçáo que motivou o desenvolvimento e a estruturaçáo das intervençóes do terapeuta ocupacional junto ao grupo de acompanhantes, cujos principais aspectos e reflexôes foram descritos a seguir.

\subsection{Intervenções terapêuticas ocupa- cionais com os acompanhantes das crianças internadas na UTI pediátrica}

O grupo de acompanhantes da UTI Pediátrica teve início em outubro de 2013, com frequência semanal e duração de uma hora cada encontro. $\mathrm{O}$ grupo ocorria às segundas-feiras, das $14 \mathrm{~h} 30$ às 15h30. Foi estrategicamente planejado para ocorrer nesse horário, a fim de garantir maior adesão dos acompanhantes, já que este é o período que antecede o horário de visita dos pais e passagem do boletim médico. Os atendimentos ocorreram durante nove meses.

Os acompanhantes das crianças internadas eram, prioritariamente, as mães. Havia uma pequena parcela de participantes com outros graus de parentesco, sendo eles pai, tia e avó.

A proposta das intervençôes terapêuticas ocupacionais junto ao grupo foi proporcionar uma melhor qualidade de vida durante esse período de difícil enfrentamento.

A instituição em que um grupo é inserido exerce uma influência significativa, já que fatores como o perfil da clientela atendida, os objetivos do serviço e do tratamento, o número de participantes, os critérios de encaminhamento e a seleção dos integrantes são de extrema relevância (CUNHA; SANTOS, 2009).

Dessa forma, os objetivos do trabalho foram: possibilitar ao grupo de acompanhantes a saída do ambiente da UTI, construir um espaço mais humanizado que favorecesse o diálogo e a troca de experiências entre os acompanhantes, orientar quanto às condiçóes de saúde da criança e, concomitantemente, preparar para etapas subsequentes do tratamento, auxiliar na reorganização da rotina da casa mesmo à distância, fomentar a ampliação da rede de apoio familiar e/ou social, e criar espaços dirigidos ao autocuidado. Em estudo sobre a atuação da Terapia Ocupacional em hospital, Giardinetto et al. (2009) descreve objetivos similares aos estabelecidos pelo terapeuta ocupacional neste trabalho.

Para que o grupo acontecesse, foram utilizados alguns recursos, como atividades expressivas, produtivas, de lazer e dinâmicas, a fim de abordar os temas previamente elaborados ou suprir demandas trazidas pelos próprios acompanhantes, o que corrobora com alguns estudos que descrevem recursos semelhantes na intervenção com grupos em hospital (DAHDAH et al., 2013; DITTZ; MELO; PINHEIRO, 2006). Os materiais utilizados nos encontros do grupo foram provenientes do serviço de Terapia Ocupacional do próprio hospital.

Durante os nove meses de desenvolvimento do trabalho, ocorreram 31 encontros, contando com cem participantes no total e média de, aproximadamente, três participantes por encontro.

Todas as segundas-feiras, o convite era feito aos acompanhantes que se encontravam na UTI Pediátrica, para participarem do grupo. Cerca de 15 minutos antes do início do atendimento, o terapeuta ocupacional reforçava o aviso, a fim de viabilizar o espaço de atendimento e os materiais, considerando-se o número de participantes daquele encontro.

A maioria dos atendimentos ocorreu na sala destinada aos pacientes e acompanhantes, localizada na Enfermaria Pediátrica do hospital. A sala contava com armário de materiais do serviço de Terapia Ocupacional, pia para higienização de materiais e mesa com banco. A Enfermaria Pediátrica localiza-se ao lado da UTI Pediátrica.

Alguns atendimentos ocorreram no ambiente externo do hospital, como o dia do piquenique, no qual os participantes e terapeuta ocupacional levaram pratos de doce, salgado e bebida, combinados previamente.

O número de participantes do grupo oscilava de acordo com as características das crianças internadas, combinadas com as características de cada acompanhante. Além disso, o grupo era aberto e heterogêneo.

A presença de um acompanhante no ambiente da UTI Pediátrica não é obrigatória, porém está regulamentada como direito da criança internada, no Art. 25, da seção V, da Resoluçáo n. ${ }^{\circ} 7$ de 24 de fevereiro de 2010 (BRASIL, 2010). Alguns fatores contribuem para que os pais não permaneçam na unidade. Um deles é o fato de terem outros filhos, que também dependem de seus cuidados. Além disso, há aqueles que não podem abandonar seu emprego. Tais situaçóes foram verificadas nesse trabalho com os acompanhantes.

Por outro lado, algumas crianças internadas eram procedentes de outras cidades, o que levava, sobretudo, suas mães, a permanecerem junto dos seus filhos durante todo o período de internação, 
pois não tinham disponibilidade de ir e vir de suas cidades.

Assim, os grupos iam se constituindo com o objetivo de oferecer abertura para que os integrantes se expressassem com liberdade e, gradualmente, eles se agregavam e compartilhavam histórias e condiçōes semelhantes, corroborando com as formulaçóes de Maximino (1995), para a qual o grupo pode ser entendido como uma "caixa de ressonância", pois, à medida que as intervençôes são destinadas a um determinado integrante do grupo, estas podem atingir outro, o que amplia as possibilidades de intervenção, de modo que a fala de alguém ressoa e/ou afeta o próximo.

As intervençôes possibilitavam compartilhar os sentimentos vivenciados pelos acompanhantes durante o período de internação das crianças.

Conceitualmente, em Terapia Ocupacional, um grupo pode ser definido como um conjunto de pessoas em relação umas com as outras, que irão se organizar em busca de um objetivo compartilhado, a fim de que os participantes se encontrem em um mesmo local e horário, na presença do terapeuta ocupacional, para realizar uma atividade (BALLARIN, 2007). Desse modo, os participantes puderam ter trocas mútuas, compartilhar as experiências e os sentimentos vivenciados durante o período de internação das crianças.

No decorrer do processo, constatou-se que, durante os atendimentos, alguns acompanhantes apresentavam-se mais comunicativos, enquanto outros falavam pouco. Havia momentos em que alguns participantes demandavam maior atenção do terapeuta e do resto do grupo para si, na medida em que expressavam mais seus sentimentos.

Ainda, foi possível perceber que algumas pessoas apresentavam maior dificuldade com alguma habilidade exigida para a execução da atividade e eram auxiliadas por aquelas com mais facilidade.

Em cada encontro, o terapeuta planejava uma atividade ou esta era planejada a partir das ideias dos acompanhantes presentes na UTI, discutidas no atendimento anterior, no caso daqueles em que a programação de alta ainda não estava próxima. Segundo Hagedorn (2007), o grupo de atividades de terapia ocupacional é marcado pelo envolvimento simultâneo dos indivíduos na realização de uma ou mais tarefas ou atividades produtivas, criativas, ou sociais, com um propósito terapêutico específico estabelecido pelo terapeuta ocupacional.

Algumas atividades realizadas no grupo se relacionavam com as datas comemorativas ou eventos vivenciados em períodos próximos a cada encontro. Como exemplo disso, descreve-se a atividade planejada no atendimento relacionado ao Dia das Crianças (2013), no qual foi realizada confecção de bichinhos em feltro, a fim de que os acompanhantes presenteassem seus filhos internados. Alguns participantes, ao compreenderem que seus filhos passariam a data comemorativa no hospital e permaneceriam internados por muito tempo, optaram por fazer os bichinhos para seus outros filhos.

Para o Natal do mesmo ano, foi realizado artesanato com decoração de Natal: caixa de madeira com a técnica de decoupage, escolhida pelos participantes e combinada anteriormente. De acordo com Joaquim, Silvestrini e Marini (2014), é durante a realização dessas atividades em grupo que acontece o processo terapêutico ocupacional, no qual se pode entender e trabalhar as demandas apresentadas pelo grupo. A relação dialógica que se estabelece no grupo possibilita que o terapeuta construa estratégias no aqui e agora, voltadas para ação ora de orientação, ora de suporte, ora de reflexão, entre outras estratégias.

Em alguns encontros, como o que ocorreu próximo à Páscoa, no qual os participantes foram convidados a confeccionar cartôes e realizar a troca "amigo oculto", constatou-se maior interação, participação social e apoio mútuo entre eles. $\mathrm{O}$ mesmo ocorreu em atividade extra-hospitalar realizada um junho de 2014, em que se organizou um piquenique. Todos os presentes se envolveram na elaboração e na discussão da atividade.

\section{Os participantes puderam expor seus costumes e tradiçōes, falar de comidas, expressar desejos, enfim, através da execução da proposta, pôde-se criar uma interconexão de expressōes, sensações, desabafos e percepçōes sobre si, sobre o outro e sobre essa relaçáo entre todos, e assim ir tecendo ligaçôes entre diferentes possibilidades (JOAQUIM; SILVESTRINI; MARINI, 2014, p. 149).}

Todas essas atividades realizadas, incluindo dinâmicas grupais, favoreceram a sensibilização dos participantes, permitindo que os mesmos refletissem e discutissem situações de vida específicas e, sobretudo, o modo como enfrentavam a hospitalização. O enfrentamento foi definido, neste estudo, como esforços comportamentais e cognitivos do indivíduo voltados para manejar um acontecimento estressante - no caso, a internaçáo do filho -, fazendo-o compreender quais são os fatores que irão influenciar o resultado final do processo (FOLKMAN, 2011 apud RODRIGUES; POLIDORI, 2012). 
Por se tratar de um grupo heterogêneo, os novos integrantes beneficiavam-se das experiências daqueles que estavam havia mais tempo na UTI Pediátrica. Assim, os que estavam chegando enfrentavam sentimentos, medos e angústias já vivenciados pelos participantes e, deste modo, ocorria o compartilhamento das experiências.

Para Castro et al. (2001), as atividades são elementos articuladores para os indivíduos, representando oportunidades de encontro e diálogo, possibilitando o aparecimento de produçóes significativas e desalienadoras, que envolvem um sujeito inserido num determinado tempo e espaço. Ainda, as atividades são recursos que proporcionam conhecimento e experiência, auxiliam na transformação de rotinas, ampliam a comunicação e possibilitam crescimento pessoal, autonomia, interação social e inclusão cultural. Podem ser recursos para a expressão não verbal de impulsos e fantasias, diminuição do embotamento afetivo, promoção da aprendizagem e eliminação de sintomas (ISIDORO, 2000).

Os participantes fazem uma avaliação positiva da realização dos encontros durante o período que passaram na UTI Pediátrica. Os relatos evidenciaram que, durante o grupo, os mesmos puderam dividir angústias, ajudar e ser ajudados, aprender a fazer coisas novas, conhecer mais os outros acompanhantes, pensar em outros assuntos além da doença da criança internada, voltar o cuidado para si mesmos, habitar espaços fora da UTI.

\section{Considerações finais}

A família de uma criança internada em Unidade de Terapia Intensiva vivencia o sofrimento da hospitalizaçáo e a ruptura do cotidiano junto com a criança, e, desse modo, também se torna alvo para a Terapia Ocupacional.

A UTI Pediátrica do referido serviço apresenta uma população com características pertinentes à elaboração de um grupo de acompanhantes, na medida em que eles permanecem grande parte do dia numa sala, na qual contam apenas com uma televisão e não recebem o acolhimento que necessitam.

O grupo desenvolvido junto a esta população apresentou-se como heterogêneo e aberto, composto principalmente por familiares das crianças internadas, sobretudo máes. A experiência descrita revela a criação de um espaço no qual se pôde pensar em qualidade de vida aos acompanhantes, já que estes, muitas vezes, não são lembrados durante a internação de crianças.
Embora se trate de um relato de experiência e, nesse sentido, explicite algumas limitações, o trabalho em si desenvolvido foi relevante, de maneira que atingiu os objetivos propostos, já que possibilitou aos acompanhantes a saída do ambiente da UTI, construiu um espaço mais humanizado, que favoreceu o diálogo e a troca de experiências entre os acompanhantes, orientou quanto às condiçóes de saúde da criança e preparou para etapas subsequentes do tratamento, auxiliou na reorganização da rotina da casa, fomentou a ampliação da rede de apoio e criou espaços dirigidos ao autocuidado.

Dessa forma, observa-se que a proposta de um grupo foi benéfica aos acompanhantes durante a internação, de modo que criou um espaço e permitiu que pudessem oferecer apoio uns aos outros, recriar e reconstruir histórias da internação, desenvolver novas habilidades, elaborar novas formas de enfrentamento, realizar atividades que proporcionassem prazer, vivenciar datas comemorativas no ambiente hospitalar e fortalecer o vínculo com a criança internada a partir de um novo olhar para ela, pensando em suas possibilidades e potencialidades.

Além disso, do ponto de vista da Terapia Ocupacional, enfatiza-se a utilizaçâo das atividades expressivas, produtivas, de lazer e dinâmicas, que utilizaram recursos materiais essenciais para que se atingissem os objetivos relatados.

Esse estudo não se esgota com esse relato, pois se sabe que há outras diversas formas de intervenção com familiares e/ou acompanhantes de crianças internadas em sistema intensivo.

\section{Referências}

ALMEIDA, A. S. et al. Sentimentos dos familiares em relação ao paciente internado na unidade de terapia intensiva. Revista Brasileira de Enfermagem, Brasília, v. 62, n. 6, p. 844-849, 2009. Disponível em: <http://www. scielo.br/pdf/reben/v62n6/a07v62n6.pdf>. Acesso em: 9 jul. 2014.

BALLARIN, M. L. G. S. Abordagens grupais. In: CAVALCANTI, A.; GALVÃO, C. Terapia Ocupacional: fundamentação e prática. Rio de Janeiro: Guanabara Koogan, 2007. p. 38-43.

BRASIL. Lei no 8.069, de 13 de julho de 1990. Dispóe sobre o Estatuto da Criança e do Adolescente e dá outras providências. Diário Oficial [da] República Federativa do Brasil, Brasília, DF, 16 jul. 1990. Disponível em: $<$ http://www.planalto.gov.br/ccivil_03/leis/18069.htm>. Acesso em: 10 maio 2015.

BRASIL. Ministério da Saúde. Agência Nacional de Vigilância Sanitária. Resoluçăo RDC n 7, de 24 de fevereiro de 2010. Dispóe sobre os requisitos mínimos para funcionamento de Unidades de Terapia Intensiva e dá 
outras providências. Diário Oficial [da] República Federativa do Brasil, Brasília, DF, 24 fev. 2010. Disponível em: <http://bvsms.saude.gov.br/bvs/saudelegis/anvisa/2010/ res0007_24_02_2010.html>. Acesso em: 9 jul. 2014.

CASTRO, E. D. et al. Atividades humanas e Terapia Ocupacional. In: DE CARLO, M. M. R. P.; BARTALOTTI, C. C. Terapia Ocupacional no Brasil: fundamentos e perspectivas. São Paulo: Plexus, 2001. p. 41-59.

CUNHA, A. C. F; SANTOS, T. F. A utilização do grupo como recurso terapêutico no processo da terapia ocupacional com clientes com transtornos psicóticos: apontamentos bibliográficos. Cadernos de Terapia Ocupacional da UFSCar, São Carlos, v. 17, n. 2, p. 133-146, 2009.

DAHDAH, D. F. et al. Grupo de familiares acompanhantes de pacientes hospitalizados: estratégias de intervenção da Terapia Ocupacional em um hospital geral. Cadernos de Terapia Ocupacional da UFSCar, São Carlos, v. 21, n. 2, p. 399-404, 2013.

DITTZ, E. S.; MELO, D. C. C.; PINHEIRO, Z. M. M. A terapia ocupacional no contexto da assistência à mãe e à família de recém-nascidos internados em unidade de terapia intensiva. Cadernos de Terapia Ocupacional da UFSCar, São Carlos, v. 17, n. 1, p. 42-47, 2006.

GIARDINETTO, A. R. S. B. et al. A importância da atuação da terapia ocupacional com a população infantil hospitalizada: a visão de profissionais da área da saúde. Cadernos de Terapia Ocupacional da UFSCar, São Carlos, v. 17, n. 1, p. 63-69, 2009.

GOMES, G. C.; LUNARDI FILHO, W. D.; ERDMANN, A. L. O sofrimento psíquico em trabalhadores de UTI interferindo no seu modo de viver a enfermagem. Revista Enfermagem UERJ, Rio de Janeiro, v. 14, n. 1, p. 93-99, 2006.

HAGEDORN, R. Ferramentas para prática em Terapia Ocupacional: uma abordagem estruturada aos conhecimentos e processos centrais. Sáo Paulo: Roca, 2007.

ISIDORO, A. L. C. Redimensionando atividades. Revista Centro de Especialidades em Terapia Ocupacional, São Paulo, v. 5, n. 5, p. 16-21, 2000.

JOAQUIM, R. H. V. T.; SILVESTRINI, M. S.; MARINI, B. P. R. Grupo de mães de bebês prematuros hospitalizados: experiência de intervenção de Terapia
Ocupacional no contexto hospitalar. Cadernos de Terapia Ocupacional da UFSCar, São Carlos, v. 22, n. 1, p. 145150, 2014.

MAXIMINO, V. S. A constituição de grupos de atividade com pacientes graves. Revista Centro de Especialidades em Terapia Ocupacional, São Paulo, v. 11, n. 1, p. 27-32, 1995.

MENSORIO, M. S.; KOHLSDORF, M. Cuidadores de crianças e adolescentes com leucemia: análise de estratégias de enfrentamento. Psicologia em Revista, Belo Horizonte, v. 15, n. 1, p. 158-176, 2009.

MILANESI, K. et al. Sofrimento psíquico da família de crianças hospitalizadas. Revista Brasileira de Enfermagem, Brasília, v. 59, n. 6, p. 769-774, 2006. http://dx.doi. org/10.1590/S0034-71672006000600009.

MIRANDA, E. J. P.; STANCATO, K. Riscos à saúde de equipe de enfermagem em unidade de terapia intensiva: proposta de abordagem integral da saúde. Revista Brasileira de Terapia Intensiva, São Paulo, v. 20, n. 1, p. 68 76, 2008. Disponível em: <http://www.scielo.br/scielo. php?pid=S0103-507X2008000100011\&script=sci_arttext>. Acesso em: 10 jun. 2014.

MORAIS, G. S. N.; COSTA, S. F. G. Experiência existencial de mães de crianças hospitalizadas em Unidade de Terapia Intensiva Pediátrica. Revista da Escola de Enfermagem da USP, São Paulo, v. 43, n. 3, p. 639-646, 2009. http://dx.doi.org/10.1590/S008062342009000300020.

RIBEIRO, M. B. S.; BERNAL, M.; ZAPONI, E. P. G. Relato da experiência de aprimorandas do programa de terapia ocupacional em saúde mental numa enfermaria de pediatria. Cadernos de Terapia Ocupacional da UFSCar, São Carlos, v. 16, n. 2, p. 113-121, 2008.

RODRIGUES, F. S. S.; POLIDORI, M. M. Enfrentamento e resiliência de pacientes em tratamento quimioterápico e seus familiares. Revista Brasileira de Cancerologia, Salvador, v. 58, n. 4, p. 619-627, 2012.

TORRES, W. C. et al. A criança terminal: vivência no luto antecipado. In: OLIVEIRA, C. T. Exportação: o modelo ideal. Rio de Janeiro: FGV, 1987. p. 1-7.

TRIVIÑOS, A. N. S. Introdução à pesquisa em ciências sociais: a pesquisa qualitativa em educação. São Paulo: Atlas, 1987.

\section{Contribuição dos Autores}

Fernanda Rodrigues da Silva: concepção e elaboração do texto, organização das fontes, redação do texto. Maria Luisa Gazabim Simóes Ballarin: orientou a pesquisa, colaborou com a organização das fontes e a redação do texto final. José Carlos de Oliveira: colaborou com a revisão do texto. Todos os autores aprovaram a versão final do texto. 